\title{
Exploration of knowledge, attitudes and percepions regarding sexually transmitted infections among patients attending a primary health care clinic in Gauteng \\ Part 1
}

\author{
TJ Molapo, M Tech Nursing \\ Tshwane University of Technology \\ TMM Maja, D Litt et Phil \\ Department of Nursing Science, Tshwane University of Technology \\ SCD Wright, D Tech Nursing \\ Department of Nursing Science, Tshwane University of Technology
}

\section{Correspondence address:}

Dr SCD Wright

Tshwane University of Technology

Dept of Nursing Science

Private Bag x 680

Pretoria, 0001

Tel : (012) 382-5470

Fax : (012) 382-5033

E-mail : wrightscd@tut.ac.za

\section{Abstract: Curationis 30(4): 21-30}

Sexually transmitted infections are a major public health problem in South Africa. The high incidence and prevalence of sexually transmitted infections in South Africa pose a serious threat to public health for two main reasons. Firstly, the long-term consequences of these infections are a major cause of loss of health or life, and secondly, sexually transmitted infections are important co-factors in driving the human immunodeficiency virus/acquired immunodeficiency syndrome (HIV/AIDS) epidemic. The control and prevention of sexually transmitted infections has become an urgent priority. At a primary health care clinic, the nursing personnel experienced an increasing number of persons daily seeking treatment for sexually transmitted infections. The purpose of the study was therefore to investigate the knowledge, attitudes and perceptions of people seeking treatment at Stanza Bopape Clinic regarding sexually transmitted infections. The study was a contextual, quantitative survey. The population was all patients ( 15 years and older) who visited the clinic for a health-related problem during November 2004 to January 2005. The sampling method was convenient. The data gathering method was self-report using a structured questionnaire basic on current knowledge. The data analysis was done with descriptive statistics.

\section{Background, rationale and research problem}

Sexually transmitted infections are a major public health problem in South Africa (Ballard et al., 2000:1). It has been estimated that over three and a half million patients in South Africa alone seek treatment for sexually transmitted infections each year at public sector facilities. Many more are seen in private practice and occupational health services. The high incidence and prevalence of sexually transmitted infections in South Africa poses a serious threat to public health for two main reasons. Firstly, because the long-term consequences of these infections are a major cause of healthy life lost, particularly for women and children. Secondly, because sexually transmitted infections are important co-factors in driving the HIV epidemic (Wilkinson et al., 1997:1).

Though high rates of sexually transmitted infections are common globally, Landry and Turnbull (1998:1) report that 
historically, sexually transmitted infections have been overlooked in the global fight against infectious diseases. The result is a high mortality rate with premature loss of life, especially in the developing world. It is estimated that 333 million new cases of treatable sexually transmitted infections (excluding HIV/ AIDS and other viral sexually transmitted infections) occur every year, globally (Mulick et al., 2001:37).

The control and prevention of sexually transmitted infections has become an urgent priority. Sexually transmitted infections spread rapidly and if not promptly treated, can result in long-term complications. Since its detection in the West early in the 1980s, HIV/AIDS has become and remained a priority public health issue. In addition, HIV/AIDS has also directed attention away from other sexually transmitted infections and their consequences to the health and the wellbeing of the community.

At the primary health care clinic, the nursing personnel have experienced an increasing number of persons seeking treatment for sexually transmitted infections. The clinic's statistics indicated that the incidence of sexually transmitted infections, excluding HIV/ AIDS, for the period from June 2003 to May 2004 was 3782 compared to less than 2000 in the previous corresponding period. The increased rate and increased number of repeat diagnoses of sexually transmitted infections at the clinic were a concern to the registered professional nurses especially with the possibility of coexistence of HIV. The incidence of other sexually transmitted infections and their possible consequences makes it imperative that registered professional nurses working in primary health care develop specific prevention strategies to prevent sexually transmitted infections.

One strategy commonly employed to combat infectious diseases, is health education. Whilst health education is inadequate by itself, it is a key discipline that must be harnessed in any comprehensive management of primary health care concerns. Naude, Meyer \& van Niekerk, 2000:127) state that health education should move from its current disease-prevention focus and should focus more on the promotion of health. With the changed focus, the purpose would be to promote healthy behaviour before the onset of the disease. Health education to promote a healthy sexual lifestyle is central to primary prevention. The health education programmes should be built around a fully participatory basis with key local leaders, informants and families. Clients often mobilise themselves only if they are reached where they are on an equal footing (UNESCO, 2001:26).

The focus of the research was therefore to formally investigate the incidence of sexually transmitted infections at Stanza Bopape clinic and to develop community specific guidelines to reduce the incidence of sexually transmitted infections the primary health care clinic. The focus of the current article (Part I) is to report one specific aspect of the study, namely the knowledge, attitudes and perceptions regarding sexually transmitted infections in the community surrounding the primary health care clinic. Part II of this research will describe the guidelines generated from the research.

The research problem reported on in this article was as follows: What is the knowledge, attitudes and perceptions of people seeking treatment at Stanza Bopape Clinic regarding sexually transmitted infections? The purpose was to gain an understanding of the current knowledge, attitudes and perceptions of the specific community to be able to develop community specific guidelines to improve the knowledge, attitudes and perceptions of the community.

\section{Theoretical framework of the study}

The theoretical basis of the study is the Health Promotion Model as described by Pender, Murdaugh and Parsons (2002:Chapter 3). The Health Promotion Model is an integrated perspective that depicts the range of behavioural influences to be addressed in nursing interventions in order to increase healthpromoting behaviours (Pender, Murdaugh \& Parsons, 2002:75).

\section{Research methods and design Context}

The study was contextual in nature. Burns and Grove (2003:14) define contextual as a study that is done within a specific area and that the results of the study would only be valid for the situation in which the study was conducted. The study was conducted at Stanza Bopape Clinic. The clinic offers services for primary health care and is located in Mamelodi, a township northeast of Tshwane.

\section{Design}

The design chosen for the study problem is a quantitative survey. Burns and Grove (1999:56) define a quantitative survey design as the collection, integration and analysis of numerical data. The design was suitable for the research problem as numerical data was required to solve the research problem.

\section{Population}

According to Burns and Grove (1999:80), a population is the entire group of person or objects that meets the criteria the researcher is interested in studying. The target population for study problem are all patients ( 15 years and older) who visited the clinic for a health-related problem. However, the total population that attended Stanza Bopape clinic could not be included in the study due to time and financial constraints. To be able to reduce the target population, a specific period was chosen, namely from November 2004 to January 2005 to serve as the sample for the study problem (Polit \& Beck, 2004:731).

The sampling method was convenient. Brink (2002:39) refers to the convenience method as an accidental or availability sampling that involves choosing readily available people for the study. All clients, 15 years of age and older, who visited the Stanza Bopape clinic during November 2004 to January 2005 , and were willing to partake in the study were invited to participate in the study. The sample size realised as $1694(n=1694)$.

\section{Data gathering}

The data gathering method selected was self-report (Brink, 2006:146) using a structured interview (Burns \& Grove, 2003:396). A structured interview was chosen due to the possibility of illiterate participants as well as participants who could possibly not read English.

The data gathering instrument was a questionnaire. The aim of the questionnaire was to collect information on the knowledge, attitudes and perceptions of participants regarding sexually transmitted infections. The questionnaire was constructed based on 
previous instruments (Diale \& Roos, 2000:138; Reddy et al., 2004:265; Khoza, 2004:39) and the theoretical basis of the study. Aspects covered in the questionnaire was prior related behaviour, perceived benefits of action, perceived barriers to action, interpersonal influences, situational influences, immediate competing demands and a commitment to a plan of action.

The procedure for data gathering was as follows:

\section{- $\quad$ Pre-testing of the}

questionnaire. Before initiating the study, the questionnaire was pre-tested. The pre-test was done to ensure that the questionnaire elicited appropriate responses, and that the questions asked were understood correctly. The pretest of the questionnaire was conducted on patients from a nearby clinic, which had similar attributes to the study group but did not participate in the actual study. Questionnaires were handed to 20 patients at another clinic. Two changes were made to the questionnaire after the pre-test.

\section{- Permission to conduct the} study. Permission to conduct the study was requested and obtained from the facility manager.

\section{Identification and training of} the volunteer fieldworkers.

Three registered professional nurses working at the primary health care clinic volunteered to assist as fieldworkers for the study. The fieldworkers were trained before they participated in the study. The aim of the training sessions was to ensure structural coherence during the structured interviews.

\section{- $\quad$ Recruitment of the}

participants. Persons visiting the clinic for a health-related matter during the chosen threemonth period were invited to participate in the study. The interested participants were briefed individually about the study and their rights. An information leaflet was given to the participant to read or, if illiterate, explained before signing an informed consent form. Participation was entirely voluntary.

\section{- Data gathering and recording.}

A private room was used for the structured interviews. The room served to maintain privacy and confidentiality. Interviews were conducted in privacy by a trained fieldworker.

\section{Data analysis}

According to Brink (2006:170), data analysis is the ordering, categorizing, manipulating, summarizing and describing of data in meaningful terms. Descriptive statistics were used to describe and summarise information. As the questionnaire was pre-coded, the data were entered directly in a prepared spreadsheet. The stored data in the Excel format were then analysed using a SPSS 14.0 software programme.

\section{Ethical considerations}

The ethical standards proposed in the position paper of the Democratic Nursing Organization of South Africa (1991) for nursing researchers were followed. Consent to conduct the study was obtained from the Faculty Research and Innovation Committee of the Faculty of Science, the Ethics Committee of Tshwane University of Technology, and the management of Stanza Bopape clinic. All the participants were requested to complete the consent form before participating in the research. Sufficient information in an understandable language about the study was provided to all participants, and they were informed that they could withdraw from the study at any time for any reason.

Anonymity and confidentiality was ensured by numbering the questionnaires sequentially. According to Polit and Hungler (1999:35) participants have the right to fair and equitable treatment before, during, and after their participation in the study. Fair treatment was ensured by including all participants who were willing in the study in the predetermined period.

The privacy of the participants was maintained at all times. The self-respect and dignity of the participants was ensured (Parahoo, 1997:276), and participants had access to the researcher at any point during the study to clarify information and prevent misunderstandings. No harm was caused to participants in the study. The fieldworkers were registered professional nurses working at Stanza Bopape clinic and were thus known to the participants.

\section{Validity and reliability}

According to LoBiondo-Wood and Haber (2002:502), validity is the determination of whether a measurement instrument actually measures what it is purported to measure. Reliability is concerned with consistency, stability and repeatability of the information's accounts as well as the investigator's ability to collect and record information accurately (Burns \& Grove, 2003:374).

Validity and reliability was ensured by applying the following aspects:

- $\quad$ Researcher. The researcher was employed at the Stanza Bopape Clinic. A trust relationship existed between the researcher, management and participants.

- The proposal. The proposal was peer-reviewed and presented an in-depth description of how the research would be conducted.

- Questionnaire. The questionnaire used in the research study was constructed based on the elements of the knowledge, attitudes and perceptions regarding sexually transmitted infections (Diale \& Roos, 2000:138; Reddy et al., 2004: 265 \& Khoza, 2004:39).

The questionnaire was also pretested on a small number of participants from another clinic before the main data gathering. Two changes were made to the questionnaire after the pre-test.

- Fieldworkers. Trained

fieldworkers conducted structured interviews aimed at assisting the participants in completing the questionnaire.

- Period. Data were only gathered during the planned period.

\section{- Improved truth value of data.}

Anonymity and confidentiality was maintained by numbering the questionnaires sequentially. The fieldworkers were also known to the participants and a trust relationship already existed between the two groups. As the participants were addressed in a 


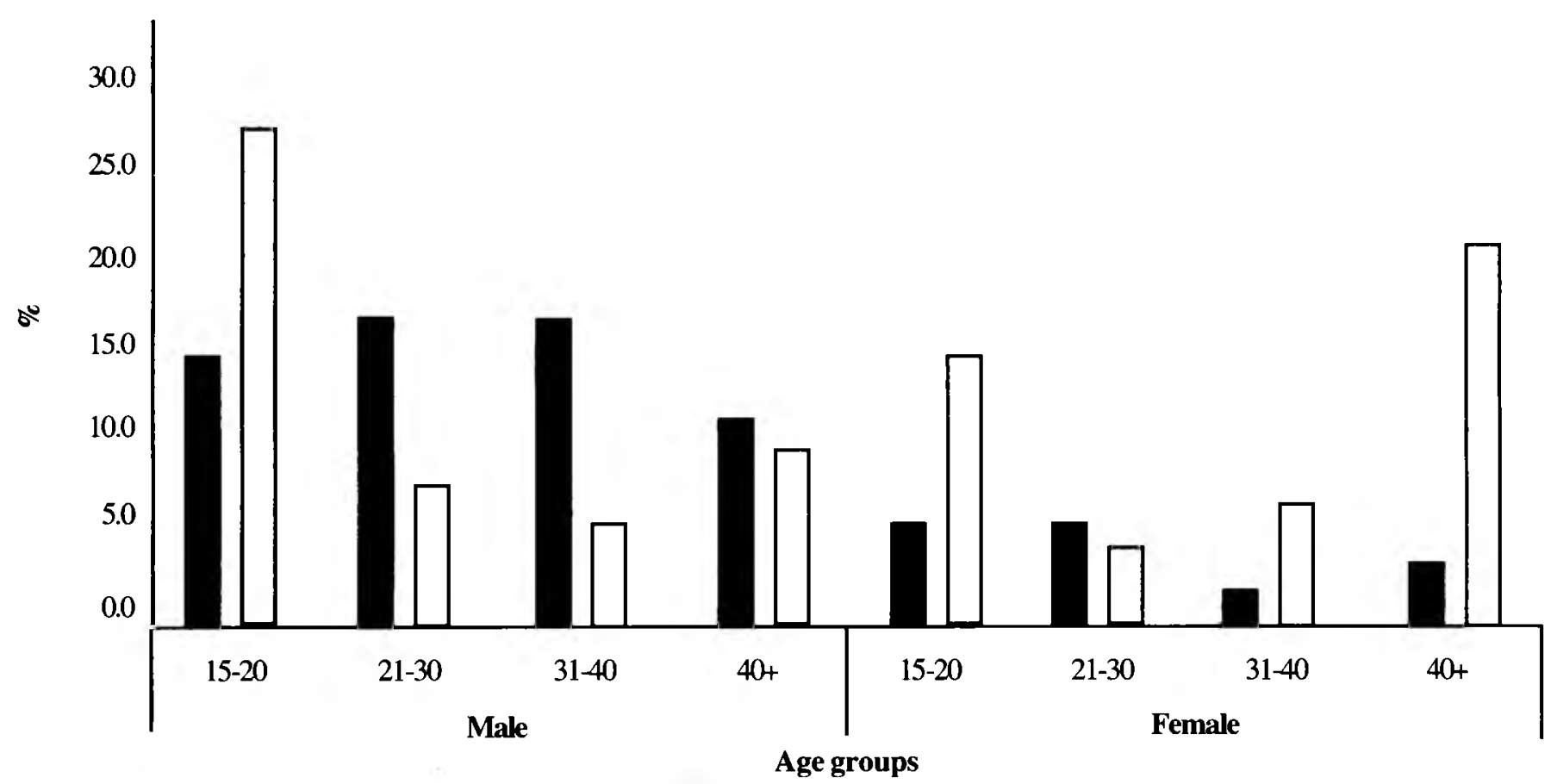

language of their choice, the possibility of misunderstanding of the questions were minimal.

\section{Results}

The results will be described in terms of the demographic profile of the sample and their knowledge, attitudes and perceptions of sexually transmitted infections.

\section{Demographic profile}

The demographic profile for the study sample $(n=1694)$ will describe the age distribution, gender, marital status, level of education, employment, religious affiliation and housing.

The majority of the participants were recruited from the 21-30 years age group (males $44 \%$ and females 56\%). The 31-40 years age group consisted of $23.8 \%$ of the study sample and females constituted $57 \%$ of this group. The total number of participants in the 15-20 age group was $327(19.3 \%)$ individuals with an equal distribution between male and female. The majority $(76.8 \%, n=1300)$ indicated that they were single. Of the single group, $51.9 \%$ were in the $21-30$ age group and $24.6 \%$ in the $15-20$ age group. If the two age groups are combined, $76.5 \%$ of young adults were single. The married group constituted $20.3 \%$ of the sample with the majority above 31 years of age.

With regards to sexual orientation, the participants were mainly heterosexual (95.1\%). Homosexuals constituted $4.1 \%$ of the sample. More females than males acknowledged their homosexuality $(6.1 \%$ versus $1.3 \%)$. Only a small number $(0.8 \%)$ indicated that they were bisexual.

The level of education of the sample was also investigated. Note that the classification secondary education, for example, does not denote the highest level but an achievement of a grade in secondary education. The majority of the study sample had a secondary education (males $74.7 \%$ and females $79.0 \%$ ). In terms of secondary and tertiary education, the females were better educated than the males. A small sample, $12.2 \%$ had only primary education. The level of reported illiteracy indicated in the study sample was only $3.4 \%$.

Concerning employment, $51.9 \%$ of the group indicated that they were not employed. Of those who indicated being employed ( $\mathrm{n}=809), 22.0 \%$ were employed as unskilled labourers and $14.7 \%$ indicated they were self-employed. The majority of the participants reported being affiliated to the Zion Christian Church and other African churches $(56 \%)$.

\section{Knowledge, attitudes and perceptions regarding sexually transmitted infections}

The knowledge, attitudes and perceptions regarding sexually transmitted infections will be presented in terms of the number of partners and the knowledge regarding various aspects of sexually transmitted infections.

\section{Number of partners}

The number of sexual partners was investigated as it was considered a practice-based question bearing light on knowledge, attitudes and perceptions. As knowledge, attitudes or perceptions do not necessarily translate into action, determining the numbers of partners would provide a suggestion of the study sample's sexual behaviour. An increased number of sexual partners would suggest an increased risk to acquire a sexually transmitted infection and possibly HIV. The majority of the participants $(81.5 \%)$ reported having one sexual partner. In terms of gender, more females $(86.6 \%)$ than males $(73.3 \%)$ indicated one partner. If all categories that indicate multiple sexual partners are combined, $16.4 \%$ of the males and $4.5 \%$ of the females indicated more than one partner. Approximately one in ten (10.1\% males and $8.6 \%$ females) of the respondents abstained from sexual intercourse. 




Figure 1 displays an exposition of the age groups and multiple sexual partners or abstinence from sexual relationships. A variable pattern exists in the age groups as well as between males and females in the same age groups. In the 15-20 age group, $15.6 \%$ of the male professed multiple sexual partners compared with only $5.1 \%$ of the females of the same age. There is an increasing tendency of multiple sexual partners in the male group until 40 years of age $(15.6 \%, 17.0 \%$, and $17.1 \%)$. The highest number of abstinent males $(27.5 \%)$ is also in the $15-20$ age group. In the female group, approximately two in ten females $(21.9 \%)$ in the $40+$ age group reported abstinence. In the 15-20 age group, only $14.7 \%$ were abstinent compared to $27.5 \%$ in the equivalent male group. Stated in opposite terms, the results indicate that $72.5 \%$ of the males and $83.3 \%$ of the females in the 15-20 age group were sexually active.

The perception of risk of contracting HIV was investigated. When cross tabulated with the number of sexual partners, the majority of the group $(n=1158)$ indicated that the risk of HIV/AIDS affected them. Of this group, $78.3 \%$ had only one partner. There were however, still $8.5 \%$ that admitted to having multiple sexual partners and $11.2 \%$ abstained from sex. Of the group $(n=510)$ who indicated that
HIV/AIDS did not affect them, $88.8 \%$ of the group indicated having one partner and $5.1 \%$ had multiple sexual partners.

The influence of the number of sexual partners on the frequency of condom use was also investigated and $36.6 \%$ of the group $(n=1369)$ who indicated having one partner did not use condoms when having sex. Infrequent use of condoms was indicated by $36.2 \%$ and only $25.9 \%$ indicated that they always used condoms. Of the group $(n=124)$ who indicated having two partners, $51.6 \%$ used condoms sometimes, $26.65 \%$ used the condoms always and $19.4 \%$ had never used condoms. Of the group $(n=27)$ who indicated having more than three partners, $48.1 \%$ used condoms sometimes, $29.6 \%$ did not use condoms and $22.2 \%$ used condoms always. The results of the study therefore provide evidence that approximately $25 \%$ of males never wear condoms, regardless of the number of sexual partners.

\section{Knowledge about sexually transmitted infections}

The participants were asked if they were knowledgeable about sexually transmitted infections, and $92.6 \%$ $(\mathrm{n}=1568)$ responded positively. A small group $(6.9 \% ; n=116)$ reported having no knowledge of sexually transmitted infections. The group who did not know about sexually transmitted infections consisted of $32.8 \%$ females compared to $67.2 \%$ males and $80.2 \%$ of this group were single.

When age was investigated with the participants' knowledge of sexually transmitted infections, of the group $(n=1568)$ who indicated knowledge of sexually transmitted infections, $45.3 \%$ were from 21-30 age group. The age group 31-40 ranked second (24.6\%) followed by the 15-20 age group (18.6\%). Investigating the group who professed no knowledge of sexually transmitted infections, most participants were in the 15-20 age group. In this group, a significant difference existed between male $(8.3 \%)$ and female $(23.0 \%)$. The results indicate that one in five young women between 15-20 years of age admitted an absence of knowledge regarding sexually transmitted infections.

To investigate the validity of the participants' claim to be knowledgeable, several content questions regarding sexually transmitted infections were asked. High correct percentages for these questions would corroborate the level of knowledge professed by the participants. The content questions focussed on the methods of 

transmitted infections. If the all incorrect and one correct response is combined in a category of not being knowledgeable enough to maintain sexual health, $61.1 \%$ of the males and $68.4 \%$ of the females would fall into this category.

The knowledge of the $15-20$ age group is once more of concern as $45.3 \%$ had no knowledge of the signs and symptoms of sexually transmitted infections. A negative trend of knowledge is evident $(45.3 \%, 26.6 \%$, $19.6 \%$ and $8.6 \%$ ).

Trends became clear when the knowledge regarding signs and symptoms of sexually

transmission, various sexually transmitted infections, signs and symptoms, complications and the prevention methods.

\section{Knowledge about transmission of sexually transmitted infections}

The participants were asked to list methods of transmission of sexually transmitted infections. Unprotected sexual contact with an infected person, direct contact with contaminated blood and other bodily fluids were considered as correct responses.

The results indicate that the majority of the participants reported only partial knowledge on the methods of transmission of sexually transmitted infections. The majority of the participants $(87.4 \%)$ knew only one method for transmissions of sexually transmitted infections. A small group ( $3.7 \%, \mathrm{n}=62$ ) could not answer the question correctly.

\section{Knowledge regarding various sexually transmitted infections}

The respondents were asked to list three different sexually transmitted infections. Any of the sexually transmitted infections were accepted as correct, for example HIV/AIDS, gonorrhoea, syphilis or Chlamydia. It was not expected of the participants to know the proper scientific name of the infection.

As indicated in the Figure 2, only $12.4 \%$ of the males and $9.1 \%$ of the females knew at least three sexually transmitted infections. There were varying levels of knowledge between male and female. A group of participants could not name any sexually transmitted infections. Though the group was small (4.6\% males and $9.1 \%$ of the females) the group translates to 122 individuals.

With regards to the independent variables, no clear trend was obtained in terms of educational level. Regarding the age groups (Figure 3), important trends did appear. The 15-20 age group had the highest percentage in terms of no correct answer $(12.5 \%)$ and one correct answer (52.3\%) and the lowest for two and three correct responses (29.7\% and 5.5\%).

\section{Knowledge of signs and symptoms of sexually transmitted infection}

To be able to determine if what the respondent considered as knowledge was valid, a question was asked on what are the signs and symptoms of sexually transmitted infections. Penile or vaginal discharge, ulcers, warts and burning on urination were considered as correct responses. More females (34.3\%) than males $(24.3 \%)$ could not list any sign or transmitted infections and number of sexual partners were cross tabulated. Almost half $(47.8 \%)$ of the group who abstained from sexual relationships, did not know any signs and symptoms of sexually transmitted infections (Figure 4). The group who had multiple sexual partners showed an increase in knowledge, with $37.7 \%$ knowing at least two signs and symptoms of sexually transmitted infections.

\section{Knowledge regarding complications of sexually transmitted infections}

Knowledge regarding complications due to sexually transmitted infections were also investigated. Again, the majority of participants $(54.7 \%$ males and $63.6 \%$ females) demonstrated lack of knowledge regarding the complications of sexually transmitted infections.

When sexual preference was investigated with the knowledge regarding the complications of sexually transmitted infections, of the heterosexual group $(n=1589)$, the majority $(61 \%)$ of the participants demonstrated lack of knowledge. Of the homosexual group $(n=66)$, a majority $(68.2 \%)$ of the participants indicated knowledge. In terms of educational level, $82.0 \%$ of the group who indicated knowledge had a secondary education compared to $73.8 \%$ 


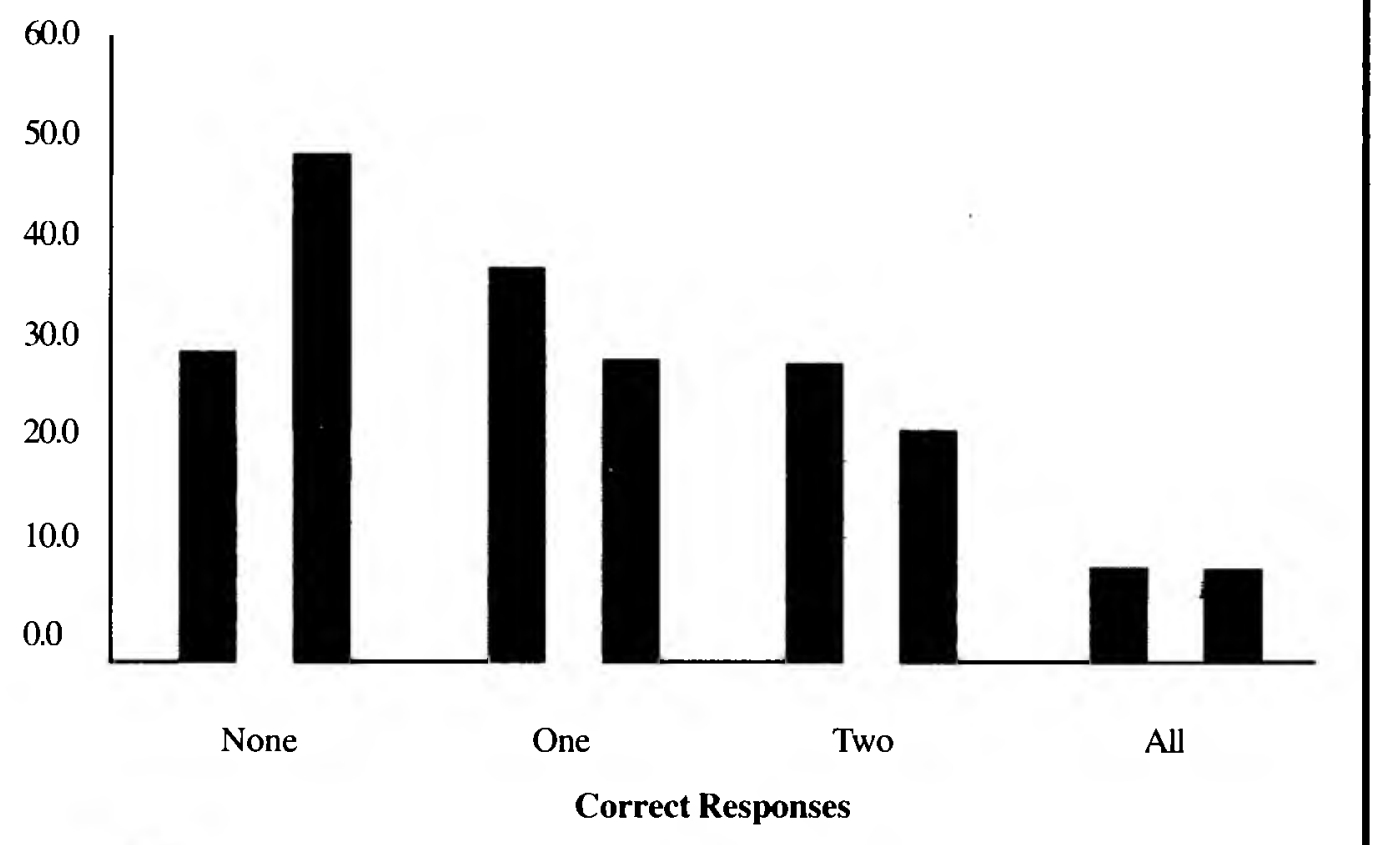

One Multiple $\square$ Abstain
FIGURE 5: Age groups and knowledge of methods of prevention ( $n=1693$ )

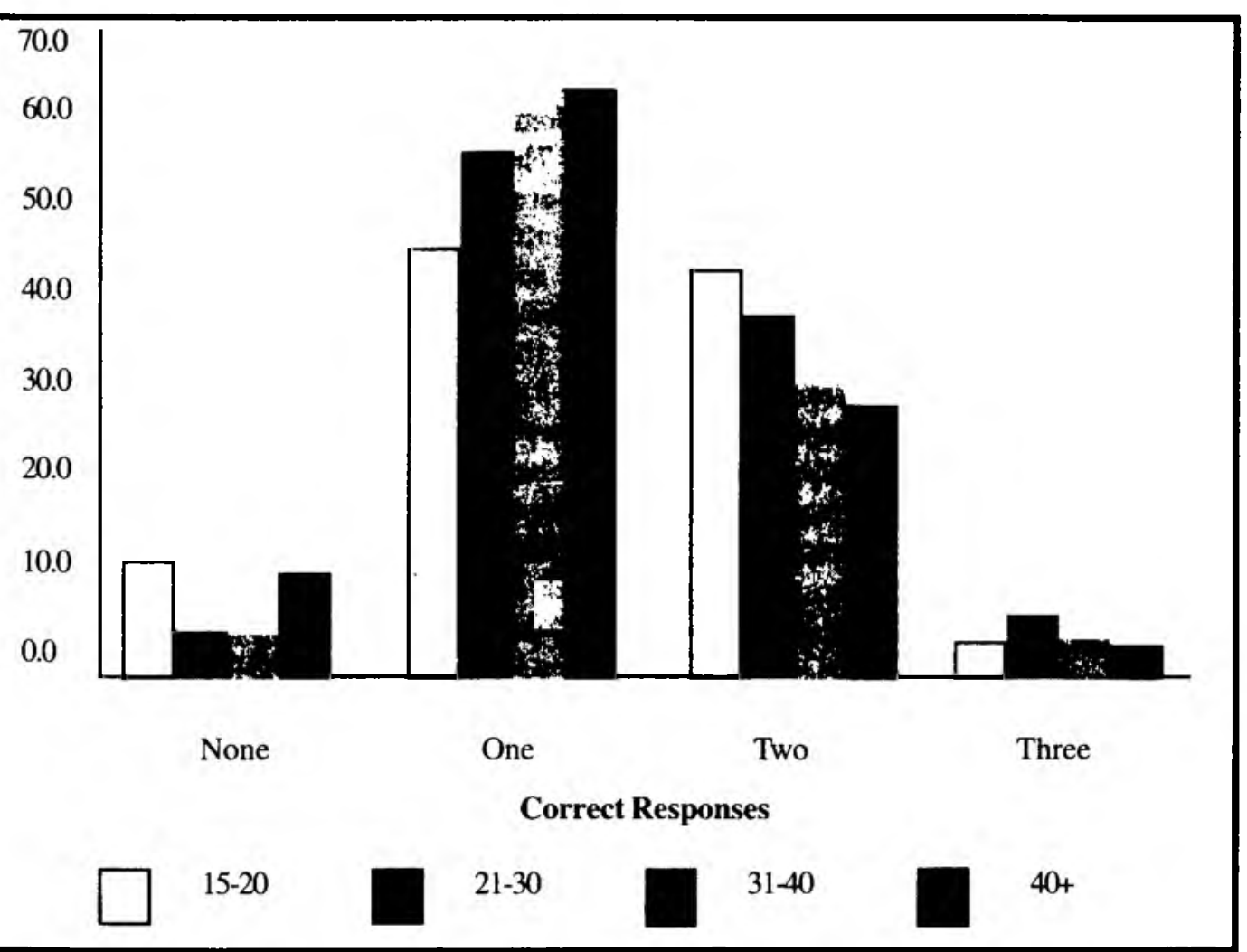

responses. Only two responses were required to indicate knowledge. The majority of the participants $(78.7 \%)$ could not list one complication caused by a sexually transmitted infection. A minority of the participants $(1.2 \%)$ responded correctly.

When the ability to list two complications of sexually transmitted infections was compared to age, the highest percentage $(82.6 \%)$ of participants who could not list the complications were in the 15-20 age group. In terms of gender, more females $(60.5 \%)$ than males $(39.5 \%)$ could not list two complications.

\section{Methods to prevent} the transmission of sexually transmitted

\section{infections}

Study participants were asked to indicate their knowledge regarding methods to prevent the transmission of sexually transmitted infections. Acceptable responses included abstinence, using condoms, being faithful to one partner and the dual method. Three correct responses were required to indicate knowledge among the respondents.

The participants were more knowledgeable regarding prevention methods (Figure 5). Less than $10 \%$ of all the age groups had no knowledge of prevention methods. Between $44.2 \%$ (15-20 age group) and $63.0 \%$

of those who indicated no knowledge.

The participants who indicated that they knew about the complications of sexually transmitted infections were asked to list the complications. A high correct percentage for this question would validate the response of the previous question. Complications, for example strictures, ectopic pregnancy, infertility, higher risk for HIV infection, and recurrent pelvic infection were accepted as correct
(31-40 age group) knew at least one method of prevention. Approximately $30 \%$ knew two methods of prevention. However, only a small group (1.6\%-3.1\%) knew at least three methods of prevention. 


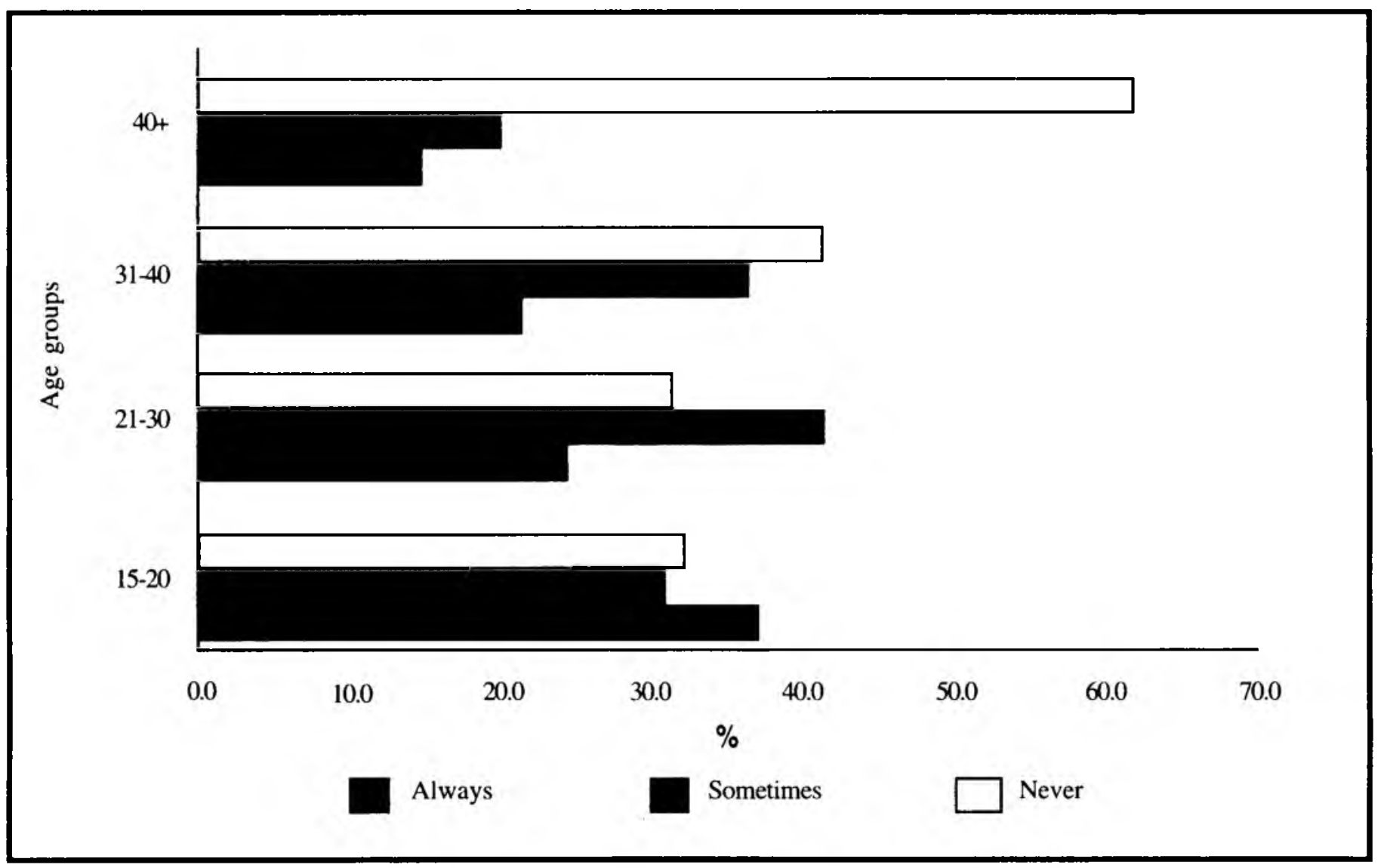

\section{Previous diagnostic tests and diagnosis of sexually transmitted infections}

The participants were asked if they were previously diagnosed with a sexually transmitted infection and $25.5 \%$ responded in the affirmative. The majority (74.2\%) did not have any previous diagnosis of sexually transmitted infection. When asked if they received any treatment, only $23.9 \%$ responded positively, of which the majority indicated compliance with the prescribed treatment.

Participants were asked to indicate if they had a previous diagnostic test for HIV, syphilis or a Pap smear for cervical infections. The overall reported level of diagnostic testing was low. The highest was testing for HIV (23\%), followed by a Pap smear (10\%) and lastly Syphilis $(5.8 \%)$. Investigating the group who reported having had a HIV diagnostic test, $28.7 \%$ of the participants were in the 41 and older age group, $25.8 \%$ in the 21 30 age groups $24.9 \%$ in the $31-40$ age groups.

\section{Knowledge of availability and location of condoms}

The important role condoms play in preventing sexually transmitted infections is crucial and cannot be overemphasized. Therefore the ability to identify areas of condom distribution was included to examine whether condoms and condom use were a priority. The participants were asked several questions regarding condoms, the availability of condoms, locations and frequency of use. When asked about access to condoms, $95.5 \%$ of the participants indicated that they had access to condoms and $95.2 \%$ reported that the condoms were readily available. In terms of the location of condoms, $79.3 \%$ of participants reported getting condoms from the clinic and $8.1 \%$ of participants indicated buying condoms from the shops. Some people indicated that they received condoms from the phone shops (7.1\%).

\section{Condom use}

The participants were asked to indicate the frequency of condom use (Figure 6). The regular and consistent use of condoms is an indicator of an action taken to prevent sexually transmitted infections. Across all four age groups, some participants were not using condoms. The highest percentage was in the $40+$ age group (63.4\%). Three in ten participants $(32.1 \%)$ in the $15-20$ age group did not use condoms. If the sometimes and never categories are combined, between $63.0 \%$ (15-20 age group) and $83.3 \%$ (40+ age group) are in danger of contracting a sexually transmitted infection. Investigating sexual preference in terms of the frequency of condom use, $38.9 \%$ of the heterosexual group and $69.6 \%$ of the homosexual group indicated not using condoms. In terms of gender, more females than males reported not ever using a condom (40.4\% females compared to $35.0 \%$ males). In addition, the availability of a personal condom was reportedly important to only a minority of the sample. The majority of the participants $(76.7 \%)$ did not carry a condom 'just in case'. Only $18 \%$ of the participants stated that they always carried a condom.

\section{Discussion}

Knowledge regarding sexually transmitted infections is an essential component in guiding individuals and communities to engage in protective and preventive actions against infections. It can be noted from the research that generally, there is a low level of knowledge amongst the patients. Though $92.6 \%$ reported that they are knowledgeable about sexually transmitted infections, the results of the 
study indicate the opposite. Evidence for the statement is as follows:

- $\quad$ Only $0.2 \%$ of the study sample could name three methods of transmission of sexually transmitted infections and $87.4 \%$ could only name one.

- $\quad$ Only $12.4 \%$ of males and $9.1 \%$ of females could name three sexually transmitted infections. A number of individuals $(n=122)$ could not even list one - not being able to name even HIV/ AIDS indicates a serious problem with the current methods of teaching in the primary health care clinic.

- $\quad$ Regarding knowledge of the signs and symptoms of sexually transmitted infections, $24.3 \%$ of males and $34.3 \%$ females could not list any signs and symptoms of sexually transmitted infections. Only $6.8 \%$ of the males and $7.0 \%$ of the females could list at least three signs and symptoms.

- The majority of the sample (54.7\% male and $63.6 \%$ female) lacked knowledge of the complications of sexually transmitted infections.

A possible reason for the low level of knowledge regarding sexually transmitted infections is suggested by Houts et al. (2005:3). The authors state that health education provided by health workers is often problematic. Professionals communicate with clients using technical jargon because of its familiarity, precision and because of a lack of non-technical words to address health issues. Therefore the information provided by health workers becomes useless as patients did not understand much about it. The current methods used at Stanza Bopape clinic include public lectures, distribution of condoms and the operations of the Love Life Centre. Very little one-to-one education about a person's specific needs occur due to lack of time. The personnel rely on the syndromic care management to manage sexually transmitted infections. These methods should be investigated to generate evidence regarding their efficacy in reducing the incidence of sexually transmitted infections. In addition, Needham et al. (2006:1) indicated that low health literacy may contribute to the high rates of sexually transmitted infections in people. However, the level of health literacy in the community being served by Stanza Bopape clinic is not known and has not been researched.

Several other implications for future interventions became apparent from the results of the study. Evidence revealed specific risks for the 15-20 age group. These risks include $15.6 \%$ of the males having multiple sexual partners. Their role models also exhibit the same behaviour. Also, the results indicate that $72.5 \%$ of the males and $83.3 \%$ of the females in the 15-20 age group are sexually active. Though sexually active, a significant group of females $(23.0 \%)$ professed no knowledge of sexually transmitted infections. The reality is an increased risk of being infected. Also, a high percentage $(45.3 \%)$ had no knowledge of the signs and symptoms of sexually transmitted infections. An even higher percentage ( $82.6 \%$ ) could not list two complications of sexually transmitted infections. In addition, there is a lack of consistent condom use (63.0\%).

\section{Recommendations}

Several recommendations emanate from the study:

- Different ways of intercultural communication with ethnic minorities should also include the handicapped using nonverbal communication, so that they can be informed about early detection and treatment of sexually transmitted infections.

- Due to the low levels of knowledge regarding sexuality amongst the participants, both the content and methods of health education offered should be investigated. Understanding of concepts such as transmission and vulnerability must be researched and evidence-based interventions developed to improve the knowledge and understanding in the community.

- $\quad$ The levels of health literacy in the community must be investigated and compared with the applicability of the current methods of teaching in the community. Evidence should be produced regarding the content and method of presentation of health promoting interventions before extensive implementation.

- Methodś to improve a culture of testing for sexually transmitted infections must be investigated.

- Curricula should focus on health education with health promotion as a primary strategy to empower the community to be in control of their own health.

- $\quad$ Age specific strategies must be explored and practiced to ensure that the registered professional nurse is proficient in teaching all age groups.

- The use of the syndromic management in the clinic for educating the community regarding sexually transmitted infections should be evaluated and adapted to ensure success.

\section{Conclusion}

Sexually transmitted infections are common and are the cause of high morbidity and mortality in South Africa. Furthermore, the reduction of the incidence of sexually transmitted infections is an important tool in the prevention of HIV/AIDS. The knowledge generated in the current study is important in terms of the age groups of infected individuals and the knowledge of the community served by Stanza Bopape clinic. The current health education practices of registered professional nurses in the primary health care clinic must be investigated as the desired outcome, namely knowledgeable clients with a low sexually transmitted infection rate is far from the current reality. Based on these findings, guidelines for reducing sexually transmitted infections will be discussed in Part 2 of this research.

\section{References}

BALLARD, R; HTUN, Y; FEHLER, G \& NEILSON, G 2000: The diagnosis and management of sexually transmitted infections in Southern Africa. 3rd ed. Johannesburg: South African Institute for Medical research.

BRINK, HI 2002: Fundamental of research methodology for health care professionals. Lansdowne: Juta.

BRINK, HI 2006: Fundamentals of research methodology for health care 
professionals. 2nd ed. Cape Town: Juta.

BURNS, N \& GROVE, SK 1999:

Understanding nursing research. 2nded. Philadelphia: WB Saunders.

BURNS, N \& GROVE, SK 2003: Understanding nursing research. 3rd ed. Philadelphia: WB Saunders.

DENOSA 1991: Ethical standards for nurse researchers, position paper. Pretoria: SANA.

DIALE, DM \& ROOS, SD 2000: Perceptions of sexually transmitted diseases among teenagers. Curationis. 23(4), Dec.:136-141.

HOUTS, PS; DOAK, CC; DOAK, LG \& LOSCALZO, L 2005: The role of pictures in improving health communication: a review of research on attention, comprehension, recall and adherence [Online]. Available from: file:/ /www.sciencedirec.com/science [Accessed: 25/04/2006].

KHOZA, LB 2004: Adolescents' knowledge, beliefs and experiences regarding sexual practices. Health SA Gesondheid. 9(3):34-41.

\section{LANDRY DJ \& TURNBULL W 1998:}

Issues in brief issue no 2 : sexually transmitted diseases hamper development efforts. New York: Alan Guttmacher Institute.

LOBIONDO-WOOD G \& HABER J 2002: Nursing research: methods, critical appraisal and utilization. 5th ed. St Louis: Mosby.

MULICK, S; MCCOY,D; BEKSINKA, M \& MOYS, A 2001: Evaluating the quality of care for sexually transmitted infections using district STI clinic assessment. Durban: Gang.

NAUDE, M; MEYER, S \& VAN NIEKERK, $S$ 2000: The nursing unit manager: a comprehensive guide. Sandton: Heinemann.

NEEDHAM, HE; WIEMANN, CM; TORTOLERO, SR \& CHACKO, MR 2006: Health literacy, reading comprehension and risk for sexually transmitted infections in young women. Journal of Adolescent Health. 38 (2), Feb: $105-110$.
PARAHOO, P 1997: Nursing research: principles, process and issues. London: Macmillan Press.

PENDER, NJ; MAUDAUGH, CL \& PARSONS, MA 2002: Health promotion in nursing practice, $4^{\text {th }}$ ed., New Jersey: Prentice Hall.

POLIT, D \& HUNGLER, BP 1999: Nursing research: principles and methods. 4th ed. Philadelphia: Lippincott.

POLIT, DF \& BECK, CT 2004: Nursing research: principles and methods. 7th ed. Philadelphia: Lippincott.

REDDY,P; MEYER-WEITZ, A; VAN DEN BORNE, B; KOK, G \& WEITJTS, $W$ 1999: The learning curve: health education in STI in South Africa [Online]. Available from: file:/l E: $\backslash$ STI\%20health20education.htm [Accessed: 10/05/2005].

UNITED NATIONS EDUCATIONAL SCIENTIFIC AND CULTURAL ORGANISATION 2001: A cultural approach to HIV/AIDS prevention and care, culturally appropriate information Education/Communication elaboration \& delivery. UNESCO.

WILKINSON, D; RAMJJE, G; STURM, AW \& KARIM, SA 1997: Reducing South African hidden epidemic of sexually transmitted infections. South Africa: Medical Research Council. 